\title{
The relationship between birth order and frequency of criminal record with stress and attention deficit / hyperactivity symptoms in thieves
}

\author{
Ghaem Salehpoor ${ }^{1}$, Ghasem Salehpoor ${ }^{2}$ \\ 1- MA in Criminal Law and Criminology, Department of Criminal Law and Criminology, Guilan Science and \\ Research Branch, Islamic Azad University, Rasht, Iran. \\ 2- PhD Candidates in Clinical Psychology, Department of Clinical Psychology, Shiraz University, Shiraz, Iran \\ (Corresponding Author). \\ E-mail: MSalehpoor.ClinPsy@gmail.com
}

Received: 19/08/2019

Accepted: 08/12/2019

\begin{abstract}
Introduction: The birth order and the frequency of criminal record can be factors affecting on the stress and attention deficit / hyperactivity of the thieves.

Aim: The present study evaluates the stress and attention deficit / hyperactivity symptoms in a group of thieves in terms of birth order and frequency of criminal record.

Method: This research was a causal comparative study in which 100 individuals commited theft who in the years 2015-2016 in Rasht central prison were punished by non-random targeted sampling were selected. Samples by the legal and demographic variables inventory, the stress scale, Conners' adult attention deficit / hyperactivity disorder rating scale-self-report-screening version, and the Wender Utah rating scale were studied and data were analyzed using multivariate analysis of variance and univariate analysis of variance.

Results: With the exception of the relationship between birth order with Conners' attention deficit and the frequency of criminal record with Conners' hyperactivity impulsivity $(\mathrm{P}>0.05)$, other components of Conners' attention deficit hyperactivity and Wender childhood attention deficit hyperactivity in second and third children, and individuals with two, three or more criminal records is more than the first born and people with one criminal record $(\mathrm{P}<0.05)$. Meanwhile, none of these groups showed a difference in stress level $(\mathrm{P}>0.05)$.

Conclusion: The birth order and the frequency of criminal record can have a significant relationship with the representation of attention deficit / hyperactivity symptoms of thieves. Therefore, monitoring, evaluation and psychological intervention of these individuals with the aim of reducing impulsive behaviors will be recommended.
\end{abstract}

Keywords: Theft, Birth order, Psychological stress, Attention deficit hyperactivity disorder

How to cite this article : Salehpoor Gh, Salehpoor Gh. The Relationship between Birth Order and Frequency of Criminal Record with Stress and Attention Deficit / Hyperactivity Symptoms in Thieves. Shenakht Journal of Psychology and Psychiatry. 2020; 6 (6): 1-16 .URL: http://shenakht.muk.ac.ir/article-1-703-fa.pdf

Copyright $\odot 2018$ the Author (s). Published by Kurdistan University of Medical Sciences. This is an open access article distributed under the terms of the Creative Commons Attribution-Non Commercial License 4.0 (CCBY-NC), where it is permissible to download, share, remix, transform, and buildup the work provided it is properly cited. The work cannot be used commercially without permission from the journal. 


\title{
رابطه ترتيب تولد و تعدد سابقه كيفرى با استرس و علائم نقص توجه - بيش فعالى در سارقين
}

\author{
قائم صالح يور'، قاسم صالح يور' \\ ا.كارشناسى ارشد حقوق جزاو جرم شناسى، گروه حقوق جزاو جرم شناسى، واحد علوم و تحقيقات گيلان، دانشكاه آزاد اسلامى، رشت، ايران.

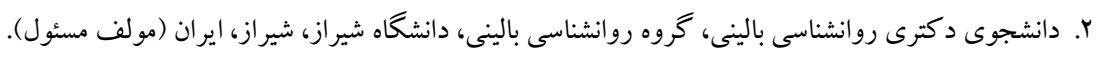 \\ ايميل: MSalehpoor.ClinPsy@gmail.com
}

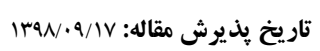

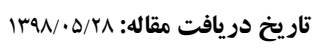

جكيده

مقدمه: ترتيب تولد و تعدد سابقه كيفرى مى توانند از عوامل مؤثر بر ميزان استرس و نقص توجه-بيش فعالى سارقين باشند.

هدف: مطالعه حاضر به بررسى ميزان استرس و علائم نقص توجه-بيش فعالى برحسب ترتيب تولد و تعدد سابقه كيفرى در گروهى از سارقين مىيردازد.

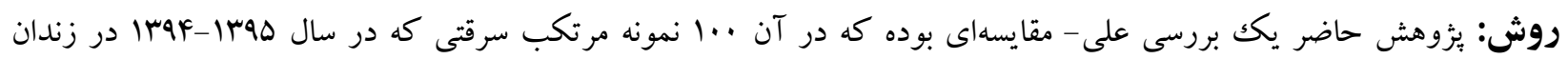

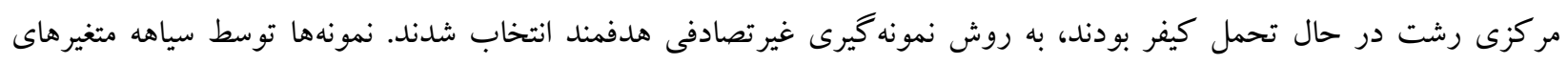

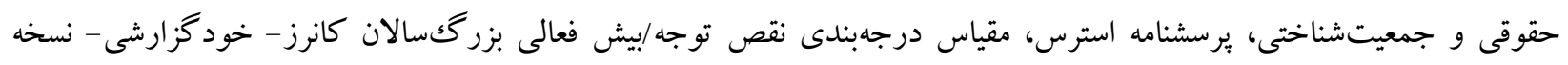

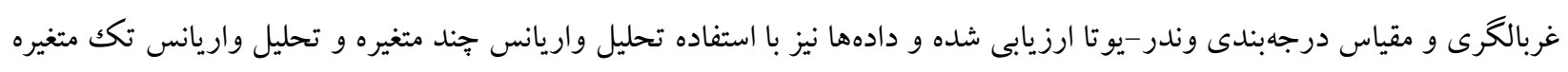
تحليل شدند.

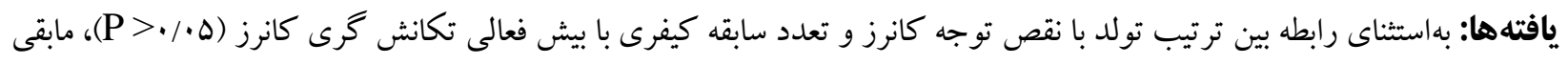

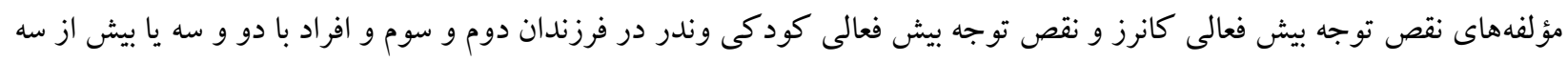

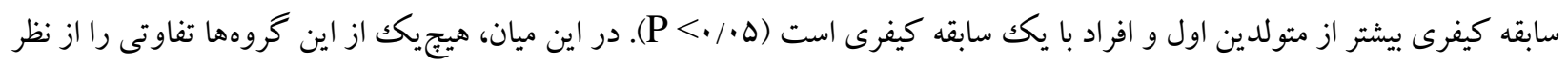

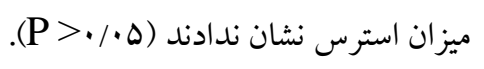

نتيجه كيرى: ترتيب تولد و تعدد سابقه كيفرى مىتواند رابطه معنى دارى با تظاهر علائم نقص توجه-بيش فعالى سارقين داشته باشند.

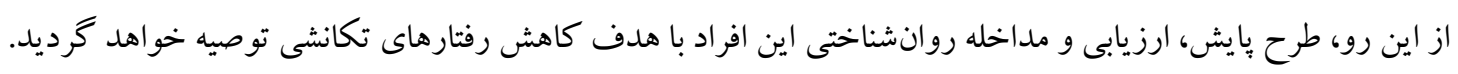

$$
\text { كليد وازهها: سرقت، ترتيب تولد، استرس روانى، نقص توجه - بيش فعالى }
$$


آينده خود باشند (مارينى و كورتز با، (1)

مقلd d

مطالعات گذشته گوياى آن بوده است كه فرزندان اول سطوح بالاترى از استرس را تجربه نموده، در حالى كه

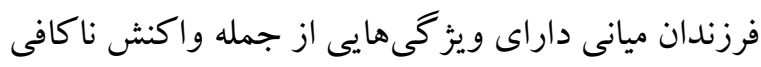
در مقابل مشكلات اجتماعى و عدم احساس تعلق مى باشند؛ فرزند آخر نيز از خصايصى همجون محبوبيت و خلاقيت برخوردار بوده و احتمال بالاى ابتلا به اختلال روانى را دارند؛ تكك فرزندان هم ويزّكىهايى نظير نياز بيشتر به بيشرفت، علاقمند به ادامه تحصيل و مشكلات رفتارى را در خود برورش مىدهند (كانديف بـ، با.ب). بر همين اساس، با بررسى يك نمونه بالينى در اسِانيا

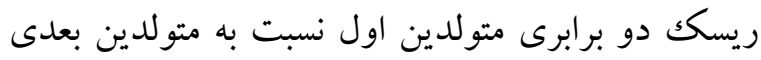

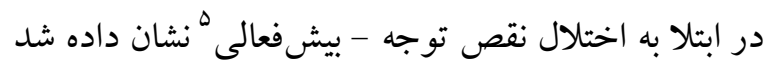
(مارين، سكو، سرانو، گارسيا، گومز ونى "و همكاران،

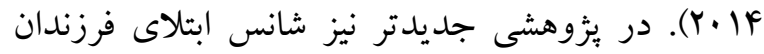
اول به نقص توجه-بيش فعالى بالاتر كزارش شد

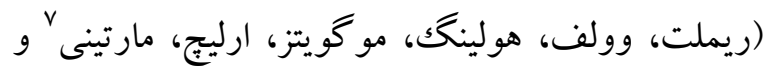

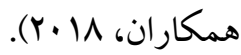
در سوى ديخر، روابط دوسويه تعدد ارتكاب جرائم و شاخصهاى روانى نيز از گذشته تاكنون جالشبرانگيز بوده و كزارشهاى متناقضى مستند يافته است. در اين باره، مجرمانى كه يس از ارتكاب جرم در فر آيند مراحل قانونى محاكمه و محكوم گردند عرفا سـابقدار (داراى ييشينه كيفرى) محسوب شده و ممكن است بر اساس قوانين علاوه بر تحمل كيفـر براى مدتى از برخى حقوق

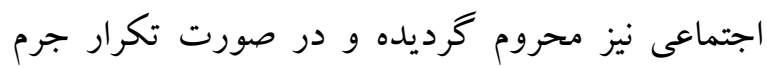
مشمول مقررات تشـديد مجازات، عدم برخوردارى از

${ }^{3}$ - Marini \& Kurtz

${ }^{4}$ - Cundiff

5 - Attention Deficit Hyperactivity Disorder

6- Marín, Seco, Serrano, García, Gómez \& Ney

7- Reimelt, Wolff, Hölling, Mogwitz, Ehrlich \& Martini

1- Damian \& Roberts

${ }^{2}$ - Govek 
كذاشتن كارها، عدم يشتكار، مشكل حفظ تمركز و نابسامان بودن جلوه گر مىشود.

علاوه بر اين، نقص توجه-بيش فعالى در كودكى نيز به

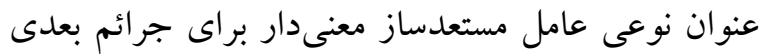

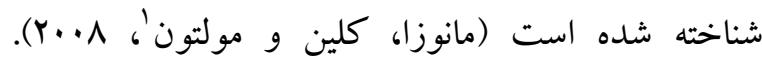
نخستين بار مطالعات اوليه در دهه هشتاد اين بيوند را نشانه رفته و با ارزيابىهاى بيخيرانه در مقاطع مختلف سنى نشان دادند كه بسران مبتلا به نقص توجه-بيش فعالى در سنين

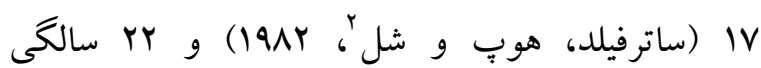
(ساترفيلد و شل، 199V) از نرخ بالاترى در دستخيرى و

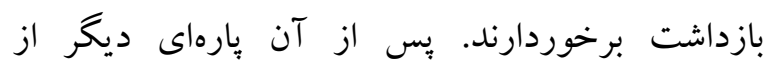
مطالعات دريافتند كه در بروندهاى، نقص توجه-بيش برد فعالى گروهى از كودكان ارجاع شده به كلينيك، كزارشهاى بيشترى درباره ارجاع به دادگًاه نسبت به

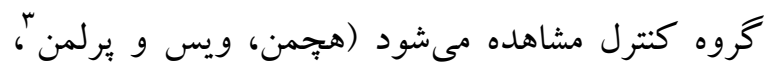
1914 ) و اين نتيجه در بزوهشى ديخر نيز تكرار شد

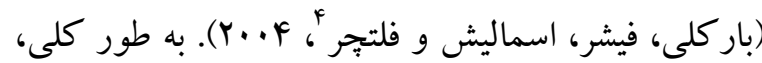
با وجود اهميت وافر توجه به جوامع مستعد ارتكاب جرائم و ارزيابى عوامل زمينهساز، تاكنون در داخل مطالعه شاخصى در خصوص آنجه اشاره شد استناد نيافته است و تا اين تاريخ نيز تنها جند مطالعه معدود به بررسى ترتيب تولد و نقص توجه-بيش فعالى برداختند كه عمدتاً

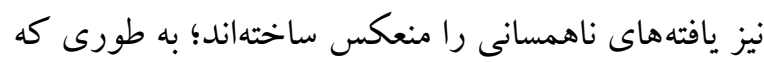
برخى از يزوهشها روابط بين ترتيب تولد و نقص توجهبيش فعالى را نشان داده (ريملت، وولف، هولينگك، مو گويتز، ارليج، مارتينى و همكاران، 11 إب؛ مارين،

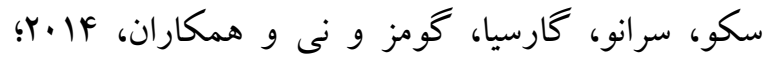

حق تعليق اجراى حكم يا عفو و آزادى مشروط كردند (نجابتى، ||جو|). در اين ميان، بيشينهُ كيفرى و تعدد جرمهاى ارتكابى از معيارهـاى قـديمى سـنجش شـدت جـرم، ميزان خطر مجرمـان و تعيسين مجـازات بـه شـمار مى آيـد و ديدكاههاى متفاوتى در اين زمينه وجود دارد كه بر مبناى ديد گاه مجازات استحقاقى، هـدف مجـازات، تناسبسازى ياسخ كيفرى با ميزان صدمه و آسيبى است

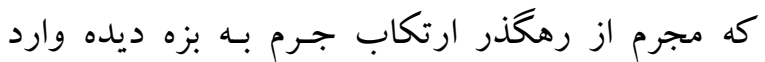

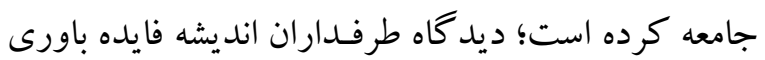
مجازات بر اين عقيده است كه هدف از مجازات جلو گيرى از تكرار جرم، اصلاح و درمان مجرم، بازدارى لئ ديخر افراد اجتماع از ارتكاب جـرم و حمايت از جامعه در برابر رفتارهاى مجرمانه است و سرانجام از منظر ديد كاه مديريت خطر، بيشينه كيفرى، نوع و تعدد جرم هاى ارتكابى و مجازاتهاى اعمال شده يِيشين و ميزان اثربخشى آنها معيار بسيار مهمى در جهت شناسايى و تفكيك مجرمان خطرناكى از مجرمان غيرخطرناكs و تعيين مجازات جرم جديد آنان است (فرجيها، عابدىنزاد

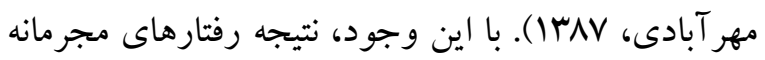
عليه اشخاص عمدتاً در قالب نوعى آسيب جسمانى / روانى تظاهر مىيابد، اما در مواردى رفتار ارتكابى ممكن است به ايجاد ترس و استرس در بزهكار منتهى گردد؛؛ ترس از اينكه در آيندهاى نزديك مجازات از جانب

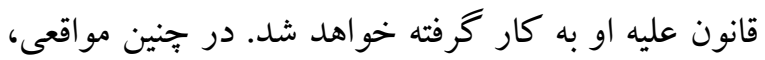
بزهار بدون ارتكاب اقدامى عليه ديكران (نظير اينكه صدمهاى وارد آورد)، دجار نوعى استرس روانى مىشود، به نحوى كه مىتوان كفت كه تماميت روانى وى مورد تهاجم قرار كرفته است و علائمى هميجون نيمه كاره

1- Mannuzza, Klein \& Moulton

2 - Satterfield, Hoppe \& Schell

3. Hechtman, Weiss \& Perlman

${ }^{4}$ - Barkley, Fischer, Smallish \& Fletcher 
محكوميت كيفرى ناشى از ارتكاب سرقت و برخوردارى از حداقل سواد لازم به منظور تكميل ابزار برّوهش. معيارهاى خروج از مطالعه نيز عبارت بود از اعمال مجرمانهاى غير از ارتكاب سرقت و محكوميت كيفرى ناشى از آن و وجود هر گونه بيمارى جسمانى همراه. در فرآيند جمع آورى و ارزيابى نمونهها، ابتدا به توضيح دلايل و نحوه انجام يزوهش براى آزمودنىها برداخته مىشد، به آنها اطمينان داده مىشد كه اطلاعات آنها محرمانه خواهد ماند و به طور ويزه نيز اعلام شد كه امتناع آنها از شركت در مطالعه نيز تأثيرى در روند كذران دوران محكوميت آنان نخواهد داشت و سرانجام بِ از از اخذ رضايت از آزمودنىها، فرآيند ارزيابى آنها آغاز مى گرديد. در مطالعه حاضر براى توصيف دادهها از شاخصهاى آمار توصيفى نظير فراوانى، درصد، ميانگين و انحراف معيار استفاده شد و در بخش آمار استنباطى نيز به منظور تحليل دادههاى يُوهش از تحليل واريانس جند متغيره براى محاسبه اثرات ترتيب تولد و تعدد سوابق كيفرى بر مؤلفههاى نقص توجه بيشفعالى بزرگكسالان (نقص توجه، بيش فعالى تكانش گرى و شاخص نقص توجه / بيش فعالى) بهره گرفته شد. علاوه بر اين، تحليل واريانس تكك متغيره نيز به منظور محاسبه اثرات ترتيب تولد و تعدد سوابق كيفرى بر استرس، نقص توجه بيث فعالى كودكى و نقص توجه بيش فعالى تكانش گرى بكار برده شد. با توجه به اين كه مؤلفه مجموع نقص توجه بيش فعالى تكانش گرى از حاصل جمع دو مؤلفه نقص توجه و بيش فعالى تكانش گرى به دست مى آيد و از شيوه نمره گذارى نامتجانسى نسبت به سه مؤلفه ديخر يرسشنامه كانرز برخوردار است، بنابراين بررسى اثرات

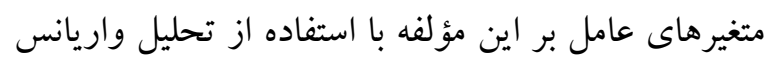

كاربالو، كارسيا-نيتو، آلوارز-گارسيا، كارو-كانيزارس،

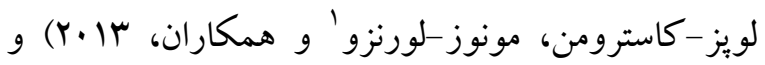
پارهاى هم نتايجى در جهت رد آن بدست آوردند

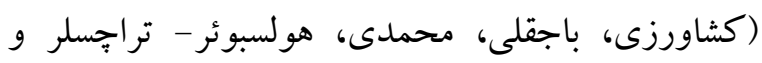

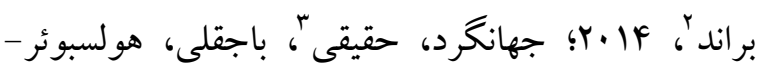

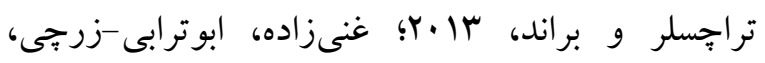

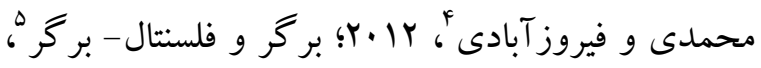

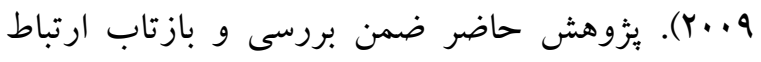
ترتيب تولد، تعدد سوابق كيفرى و شاخصهاى روانى، كزارشهاى منتشره بيشين را نيز گسترش خواهد داد و جنين امرى مىتواند تصويرى جامعتر از اثرات عوامل

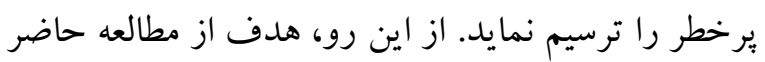
ارزيابى ميزان استرس ادراكك شده و علائم نقص توجهبيش فعالى برحسب ترتيب تولد و تعدد سابقه كيفرى در كروهى از افراد مرتكب سرقت است.

\section{روش - ماش}

يزوهش حاضر يكك طرح على - مقايسهاى بوده كه بر

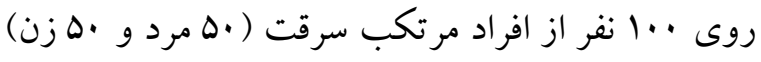
به روش نمونه گيرى غيرتصادفى هدفمند در زندان مركزى رشت واقع در استان گيلان صورت يذيرفت. جامعه آمارى اين مطالعه نيز متشكل از كليه زندانيان زن و

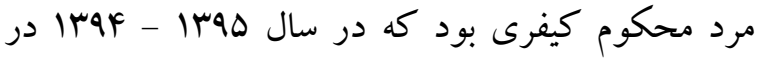
زندان مركزى رشت در استان گيلان در حال تحمل كيفر بودند. در اين ميان، محيط اجراى اين بئوهش زندان مركزى رشت بود و معيارهاى ورود به مطالعه نيز شامل

\footnotetext{
1. Carballo, García-Nieto, Álvarez-García, Caro-Cañizares, LópezCastromán \& Muñoz-Lorenzo

${ }^{2}$ - Keshavarzi, Bajoghli, Mohamadi, Holsboer-Trachsler \& Brand

3 - Jahangard \& Haghighi

4- Ghanizadeh, Abotorabi-Zarchi, Mohammadi, \& Firoozabadi

5 - Berger \& Felsenthal-Berger
} 


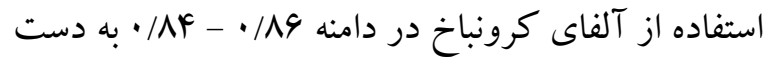

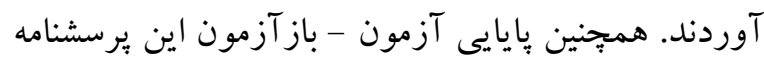

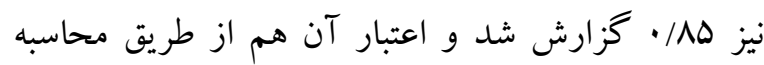
همبستخى برسشنامه استرس ادراك شده و مقياسهاى با علائم مشابه در دامنه V9/ • - DY/ • به دست آمد (كوهن، كاماركك و مرملشتين، س4911). در ايران نيز طى بثزوهشى

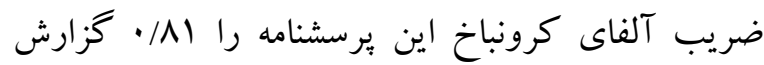

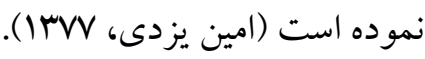

مقياس درجهبندى نقص توجه / بيش فعالى بزركىسالان

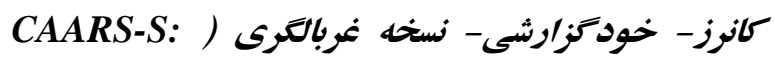
SV مقياس درجهبندى نقص توجه / بيش فعالى بزرك سالان كانرز استفاده شده است كه حاوى سنجههاى علائم نقص توجه / بيشفعالى بر مبناى راهنماى تشخيصى و آمارى اختلالهاى روانى - ويرايش جهارم (شامل نقص توجه يا

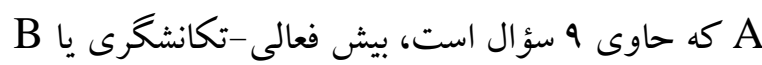
كه حاوى 9 سؤال است و مجموع علائم نقص توجه و بيش فعالى تكانش كرى يا C كه از حاصل جمع A و B به دست مى آيد) و شاخص نقص توجه / بيش فعالى (يا

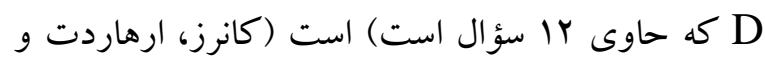

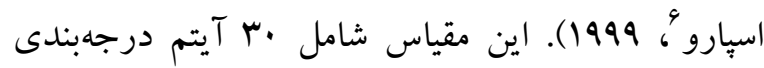
شده در مقياس ليكرت است. در اين مقياس علائم بهوسيله آزمودنى در قالب گزينههاى اصلاً، هرگز ( •)،

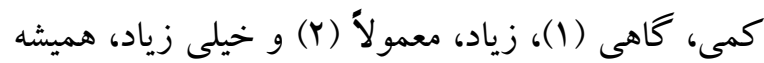

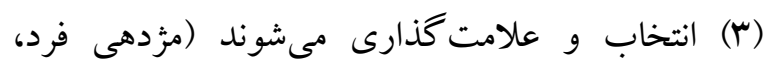

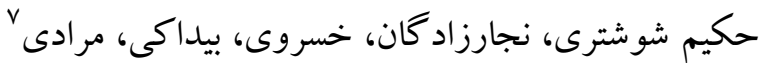

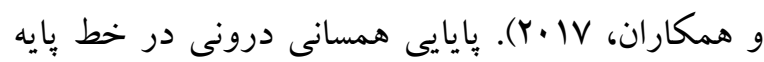

5. Conners' ADHD Rating Scale-Self-Report: Screening Version (CAARS-S: SV)

${ }^{6}$ - Conners, Erhardt \& Sparrow

7- Mozhdehi Fard, Shooshtari, Najarzadegan, Khosravi, Bidaki \& Moradi
تكك متغيره بررسى شد. همجنين به منظور بيى بردن به

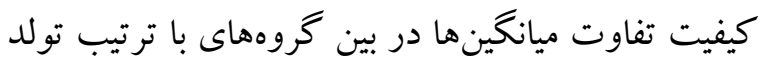
و سابقه كيفرى مختلف از آزمون تعقيى حداقل تفاوت

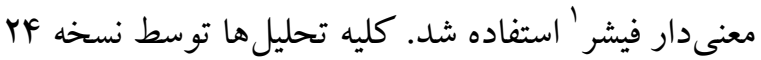
نرم افزار SPSS صورت گرفت.

ابز إد سياهه خود مزارشى متغيرهاى حقوقى و جمعيتشناختى:

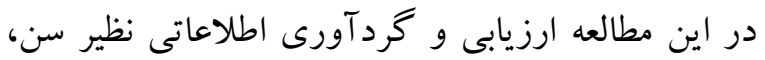
وضعيت تأهل، تحصيلات، محل سكونت، حكى دريافتى، ميزان كيفر سيرى شده و سابقه محكوميت زندان توسط يكك سياهه محقق ساخته از متغيرهاى حقوقى و جمعيتى صورت كرفت.

فرم ر| سؤالى برسشنامه استرس ادراكى شله (PSS)

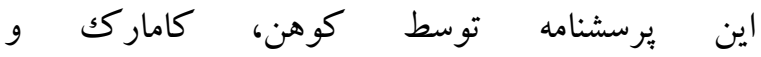

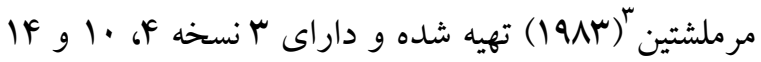
مادهاى است كه براى سنجش استرس عمومى دركك شده

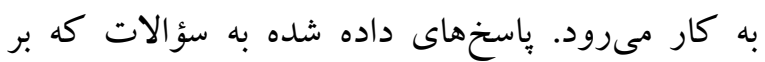
اساس طيف ه درجهاى ليكرت بوده، به صورت هر زز ="،

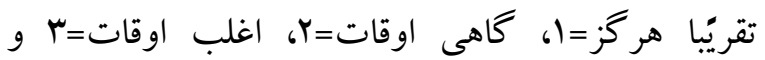
بسيارى از اوقات= أمره كذارى مي شود و دامنه نمرات آن نيز بين · تا وه است. نمرات بالاتر نشانكر استرس ادراكك شده بيشتر است. بايد خاطر نشان نمود كه نمره -

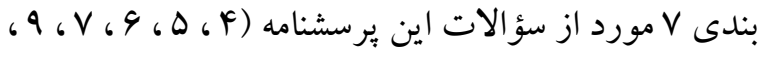

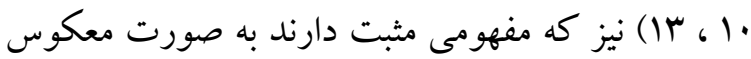

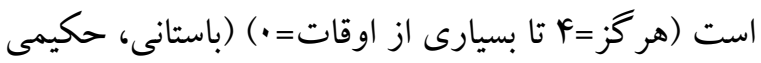

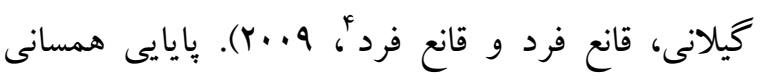
درونى هر سه نسخه يرسشنامه استرس ادراكك شده را با

\footnotetext{
1- Fisher Least Significant Difference

2 - Perceived Stress Scale (PSS)

3 - Cohen, Kamarck \& Mermelstein

${ }^{4}$ - Bastani, Gilani, Ghane-fard \& Ghane-fard
} 
آوردند (صر امى فروشانى، IMVV) و در مطالعه ديخرى نيز

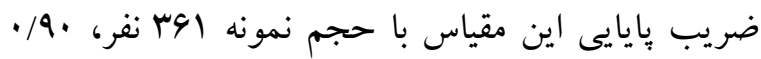

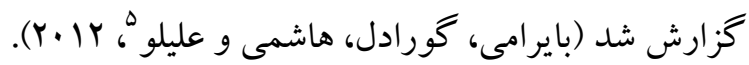

\section{يافتهها}

به طور كلى با احتساب معيارهاى ورود به بثزوهش ..1. نمونه به عنوان افراد مرتكب سرقت براى ورود به مطالعه حاضر بر گزيده شدند. بيشترين توزيع فراوانى آزمودنىها

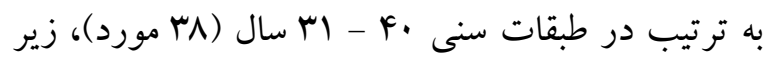

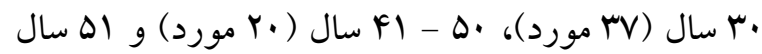
به بالا (ه مورد) بود و اكثر شركت كنندگان را افراد

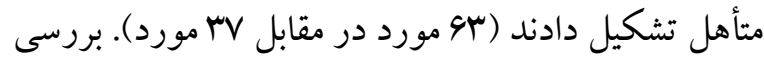
سطح آموزشى زندانيان نيز حاكى از آن بود كه بخش

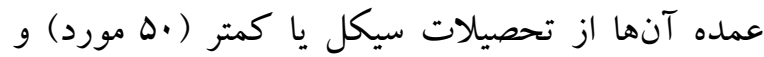
سبس دييلم و فوق دييلم (4) مورد) و ليسانس (F مورد) VI) برخوردار بودهاند. عمده آزمودنىها را شهرنشينان مورد در مقابل Y Y مورد) تشكيل داده و اكثريت آنها حكمى كمتر از ه سال (FF مورد) رادريافت نموده بودند

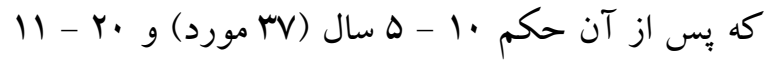
سال (19 مورد) در مرتبه بعدى قرار داشتند. سرانجام اينكه بيشتر زندانيان كمتر از Y سال (9V مورد) از دوره محكوميت خود را گذرانده بودند و سارقين با دوره

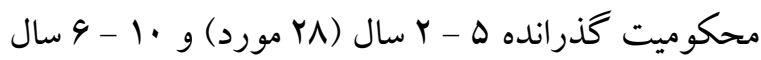

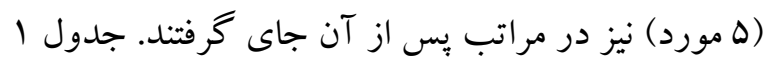

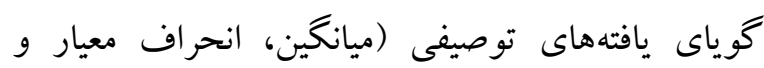
فراوانى) كليه متغيرهاى بثزوهش در سارقين برحسب ترتيب تولد و تعدد سابقه كيفرى است.

\footnotetext{
5- Bayrami, Goradel, Hashemi \& Alilu
}

براى نقص توجه AN/A •، بيش فعالى تكانش كرى AF/.6

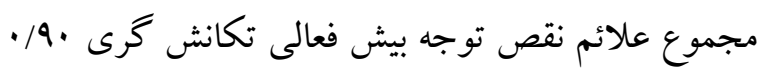
و شاخص نقص توجه بيش فعالى 94/ • گزارش شده و در

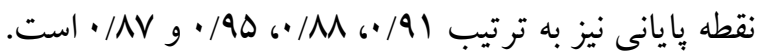
همجنين يافتها از اعتبار بالاى ييشبين اين نسخه حكايت

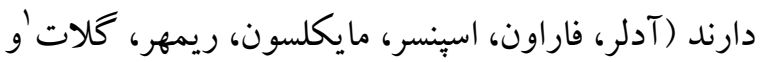

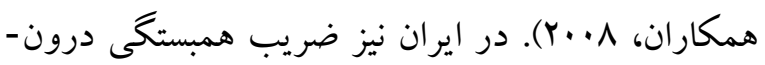
طبقهاى و آلفاى كرونباخ براى كليه مؤلفهها به ترتيب بالاتر از •V/· و •^/·• به دست آمد (داورى آشتيانى،

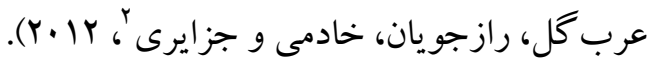
مقياس درجهبندى ونلدر-يوتا (WURS)" اين مقياس برمبناى معيارهاى يوتا كه براى تشخيص نقص توجه /

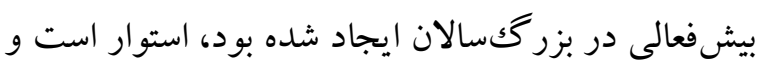

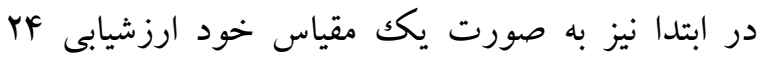
آيتمى طيف ليكرت (ينج امتيازى) همراه با سؤالهايى

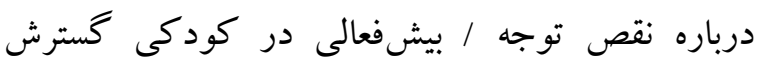

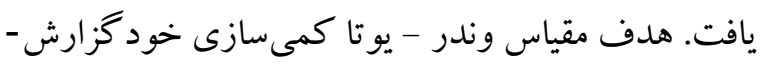
دهىهاى كذشتهنخر علائم نقص توجه / بيشفعالى شامل بيشفعالى، توجه و تكانش گرى كودكى است. در مطالعه اوليه، اين مقياس به طور مناسبى ؟^ ٪ از بيماران واجد نقص توجه / بيشفعالى ، 99 ٪ از آزمودنىهاى بهنجار و 1 \% از بيماران افسرده را شناسايى نمود. در

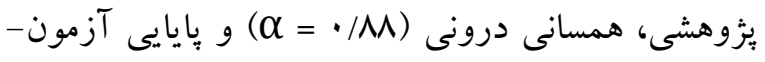

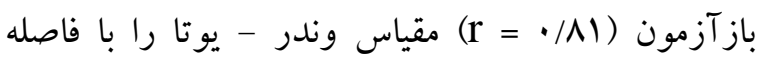
اجرايى يكك ماهه در ميان دانشجويان دانشگاهى در

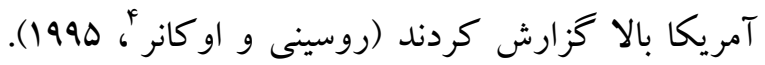
در ايران، ضريب بايايى هو/· را براى اين مقياس به دست

\footnotetext{
1- Adler, Faraone, Spencer, Michelson, Reimherr \& Glatt

2 - Davari-Ashtiani, Arabgol, Razjouyan, Khademi \& Jazayeri

3. Wender Utah Rating Scale (WURS)

${ }^{4}$ - Rossini \& O'Connor
} 
جدول ا يافته هاى توصيفى مربوط به متغير هاى يزوهش در افراد مرتكب سرقت برحسب ترتيب تولد و تعدد سابقه كيفرى

\begin{tabular}{|c|c|c|c|c|c|c|c|c|}
\hline D & $\mathbf{C}$ & B & $\mathbf{A}$ & WURS $^{*}$ & استرس & آماره & كروه & متغير \\
\hline $1 \Delta / \mid r \pm \Delta / 91$ & $r Y / F Y \pm q / Y q$ & $1 \cdot / v \Delta \pm \Delta / \cdot 1$ & $1 . / 9 \mathrm{~V} \pm \mathrm{F} / 99$ & $r q / A V \pm I V / V I$ & $r \cdot \pm \Delta / v \wedge$ & $\mathrm{M} \pm \mathrm{SD}$ & اول & \\
\hline re & re & re & re & re & rF & تعداد & & \\
\hline $19 \pm V / F Y$ & $r q / \Delta F \pm Q / r r$ & $\mid r / \Lambda 9 \pm \Delta / r \Delta$ & $\mid r / 9 \wedge \pm F / \Delta \Lambda$ & $r \Delta / \tau \cdot \pm|V / r|$ & $r|\Delta| \pm V / ৭ \Delta$ & $\mathrm{M} \pm \mathrm{SD}$ & دوم & تولد \\
\hline rv & rv & rv & rv & rv & rv & تعداد & & \\
\hline $\mid V / r \wedge \pm F / A V$ & $r F / V \pm V / F q$ & $|r / \Delta| \pm \psi / 9 \Delta$ & $\| / K q \pm F / \& r$ & $\kappa \psi / 1 \Delta \pm \mid q / \Lambda F$ & $r Q / \Gamma I \pm q / r V$ & $\mathrm{M} \pm \mathrm{SD}$ & سوم و آخر & \\
\hline rq & rq & rq & ra & rq & rq & تعداد & & \\
\hline $19 / 4 q \pm 9 / 94$ & $r r / F r \pm 1 . / . \Delta$ & $\mid r / A F \pm \Delta / M$ & $1 \cdot / \Delta q \pm \Delta / \cdot q$ & $r G / r V \pm I F / V G$ & $r q / \cdot r \pm V / r q$ & $\mathrm{M} \pm \mathrm{SD}$ & يككبار & \\
\hline rV & rv & rv & rv & rv & rv & تعداد & & \\
\hline $1 N / N \Psi \pm 9 / .1$ & $r \Delta / 9 \mid \pm \lambda / r q$ & $\mid r / T V \pm F / r \Delta$ & $|r / T r \pm F / N|$ & $r r / 9| \pm| \Delta / A r$ & $r q / \Gamma r \pm q / q v$ & $\mathrm{M} \pm \mathrm{SD}$ & دوبار & سيفرى \\
\hline$\pi$ & $r$ & $r$ & r & r & $r$ & تعداد & & \\
\hline $\mid V / r \cdot \pm \Delta / \& q$ & $r \Delta \pm V / 94$ & $\mid r / A r \pm \Delta$ & $\mid r / I V \pm r / A F$ & $F N / 9 \cdot \pm 19 / 94$ & $r Y / q \cdot \pm q / / F$ & $\mathrm{M} \pm \mathrm{SD}$ & سهبار وبالاتر & \\
\hline$\mu$. & $\mu$. & $\mu$. & $\mu$. & $r$. & r. & تعداد & & \\
\hline
\end{tabular}

حاصله نشان داد توزيع صفات متغيرهاى يثوهشى در بين نمونه با توزيع آن در جامعه نرمال بوده و تفاوت معنى دارى بين فراوانىهاى مشاهده شده و فراوانىهاى مورد انتظار وجود ندارد. جدول Y ارزيابى اثرات عاملهاى ترتيب تولد و تعدد سابقه كيفرى بر متغير استرس را با استفاده از آزمون تحليل واريانس تكك متغيرى نشان مىدهد. بررسى بر ابرى لرى واريانسهاى خطا براى متغيرهاى وابسته با بهره گيرى از آزمون لون بيانگر آن بود كه واريانس خطاى اين متغير براي در گروههاى مختلف بررسى با يكديخر برابر بوده و از از

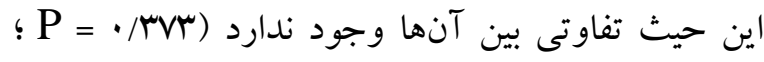

$$
\text { . }\left(F_{(1,91)}=1 / .99\right.
$$

جدول ا يافتهاى توصيفى كليه متغيرهاى يُوهشى را در كروههاى مورد مقايسه نشان مىدهند كه بر اساس آن

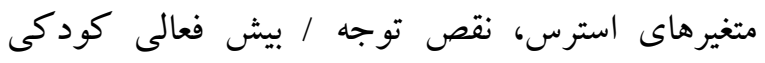
(مقياس درجهبندى وندر - يوتا)، نقص توجه (A)، بيش فعالى تكانش گرى (B)، مجموع علائم نقص توجه / بيش فعالى تكانش گرى (C) و شاخص نقص توجه / بيش فعالى (D) در فرزندان دوم بيشتر از ساير فرزندان

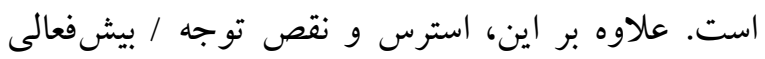
كودكى در افراد با سابقه كيفرى سه يا بالاتر و ساير

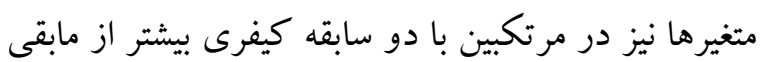
آزمودنى ها بود. جهت بررسى ييش فرض نرمال بودن توزيع داده از آزمون كلمو گروف-اسميرونوف استفاده شد كه نتايج 
جدول r تحليل واريانس تكى متغيره جهت مقايسه نمرات استرس در افراد مرتكب سرقت برحسب ترتيب تولد و تعدد سابقه كيفرى

منبع تغيير ات آزادى

\begin{tabular}{|c|c|c|c|c|c|c|}
\hline • & - /QFF & $F F / l q$. & r & $M /$ MNI $^{\prime}$ & استرس & ترتيب تولد \\
\hline$\cdot / \cdot \mathrm{VA}$ & r/GYG & IYY/Q9F & $r$ & $r F \Delta / Q \wedge \Lambda$ & استرس & سابقه كيفرى \\
\hline
\end{tabular}

معنادارى آماره F متغير نقص توجه / بيش فعالى كودكى

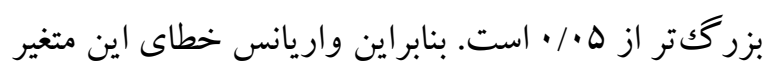
در گروههاى مختلف بررسى با يكديخر برابر بوده و از

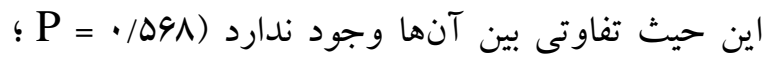

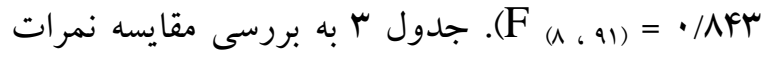
نقص توجه بيش فعالى كودكى وندر-يوتا در افراد مرتكب سرقت برحسب ترتيب تولد و تعدد سابقه كيفرى مى بيردازد.
همان طور كه جدول Y نشان ميدهد نسبتهاى محاسبه شده در مورد هيج يكك از اثرات عاملهاى ترتيب تولد و تعدد سوابق كيفرى براى متغير استرس معنىدار نشد (ه> P> P> اين مسئله بدين مفهوم است كه بين افراد مرتكب سرقت با رتبه هاى تولد و سابقه كيفرى مختلف از نظر ميزان استرس تفاوتى وجود ندارد. نتايج آزمون لون در مورد متغير نقص توجه / بيش فعالى كودكى جهت برابرى واريانسهاى خطا نيز نمايانخر آن بود كه سطح

جدول ץ تحليل واريانس تكمتغيره جهت مقايسه نمرات نقص توجه بيش فعالى كودكى وندر -يوتا در افر اد مرتكب سرقت برحسب ترتيب تولد و تعدد سابقه كيفرى

\begin{tabular}{|c|c|c|c|c|c|c|}
\hline معنى سطحى & نسبت F & مجذانكين & آزادى درجه & مجموع مجذورات & متغير ها & تغيير ات \\
\hline . & $r / Q F$. & 1. FF/IOT & r & $r \cdot \Lambda N / r \cdot r$ & نقص توجه بيش فعالى كودكى & توتيب \\
\hline$\% / \cdot r$ & $9 / 941$ & IVDG/VA. & r & $r \Delta / r / \Delta \varphi$. & نقص توجه بيش فعالى كودكى & سابقه \\
\hline
\end{tabular}

بيش فعالى در كروههاى مختلف مورد بررسى را با استفاده از آزمون تحليل واريانس جندمتغيرى نشان مى - إنى دهد. نتايج آماره ام باكس حاكى از آن بود كه ماتريسهاى كواريانس مشاهدهشه متغيرهاى وابسته در

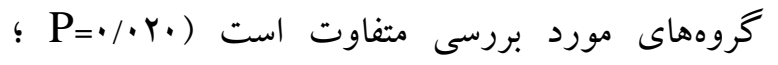
F=1/Fq4 مؤلفه هاى نقص توجه $)$

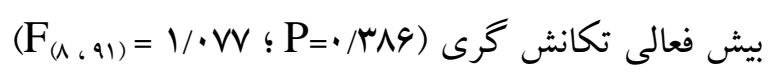

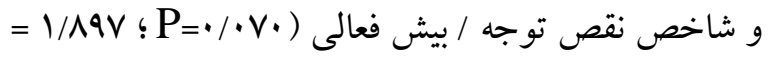

بر اساس اطلاعات حاصل از جدول "ا، نسبتهاى محاسبه شده در مورد اثر عاملهاى ترتيب تولد و تعدد سوابق كيفرى براى متغير نقص توجه / بيش فعالى

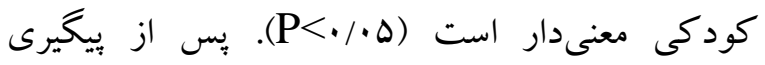
مشخص شد كه فرزندان دوم و افراد با سابقه كيفرى سه بار و بالاتر در علائم نقص توجه / بيش فعالى كودكى از ميانگين نمرات بالاترى برخوردارند (ه •/ • (P). جدول F مقايسه نمرات حاصل از اجراى سه مؤلفه نقص توجه، بيش فعالى تكانش گرى و شاخص نقص توجه / 
(F) ، a1)

جدول † تحليل واريانس جند متغيره جهت مقايسه سه مؤلفه نقصتوجه بيش فعالى بزركىسالان كانرز در افر اد مرتكب سرقت برحسب ترتيب تولد و تعدد سابقه كيفرى

\begin{tabular}{|c|c|c|c|c|c|c|}
\hline معنى سطح & نسبت F & مجذانكين & آزادى & مجذوروات & متغير ها & منبع تغييرات \\
\hline$\cdot / \cdot \Delta \Delta$ & Y/QAV & $\Delta N / A V$. & r & IIV/VF. & نقص توجه & \multirow[t]{3}{*}{ ترتيب تولد } \\
\hline.$/ .14$ & $F / 949$ & $111 / \Delta Y \Delta$ & r & $r Y r / 0.0$. & بيش فعالى تكانش گرى & \\
\hline$\cdot / \cdot 1$ & $\Delta / 1 / V$ & $|\Lambda F / \Delta| T$ & r & $\mathrm{rqQ/.TV}$ & نقص توجه بيش فعالى & \\
\hline$\cdot 1 \cdot .9$ & $r / q \vee q$ & $9 \mathrm{M} / 1 \mathrm{~F}$ & r & IAG/YTV & نقص توجه & \\
\hline$\cdot \pi \cdot$ & $1 / Y Y 1$ & $r q / r q V$ & r & $\Delta N / \Delta Q F$ & بيش فعالى تكانش گرى & سابقه كيفرى \\
\hline . Y Y & r/Ar. & $\mid r \Lambda / 1 \cdot V$ & r & rVG/YIF & نقص توجه بيش فعالى & \\
\hline
\end{tabular}

بالاترى در مؤلفه نقص توجه نسبت به افراد با سابقه كيفرى يككبار برخوردار بودند (ه</•) يبيخيرىها براى شاخص نقص توجه بيش فعالى كانرز مبين آن بود كه گروه با دو سابقه كيفرى در قياس با تك برك

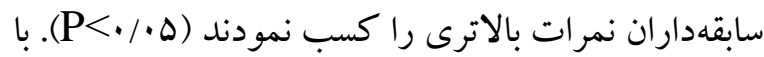
اين حال، نسبت F محاسبه شده براى اثر عامل تعدد سابقه كيفرى در خصوص علائم بيش فعالى تكانش گرى

$$
\text { معنى دار شناسايى نشد (ه • P (P). }
$$

جدول هابه محاسبه اثرات اصلى و تعاملى گروه و جنسيت بر مؤلفه مجموع نقص توجه بيش فعالى تكانش گرى با استفاده از تحليل واريانس تكك متغيره مى بردازد. نتايج آزمون لون نمايانگر آن بود كه واريانس خطاى اين متغير در گروههاى مختلف بررسى با يكديخر برابر است و و تفاوت معنىدارى از اين نظر بين آنها وجود ندارد . $\left(\mathrm{F}_{(\wedge, q 1)}=\cdot / F F \mid \leq \mathrm{P}=\cdot / \wedge q 4\right)$
همان كونه كه در جدول F بازتاب يافته است نسبتهاى F محاسبه شده در مورد اثر عامل ترتيب تولد براى علائم بيش فعالى تكانش گرى و شاخص نقص توجه / بيش فعالى و اثر عامل تعدد سابقه كيفرى بر روى علائم نقص توجه و شاخص نقص توجه / بيش فعالى معنىدار به دست آمد (ه>/ (P<). با بيخيرى مشخص شد كه فرزندان دوم و فرزندان سوم و آخر نمرات بالاترى را در مؤلفه بيش فعالى تكانش گرى نسبت به فرزندان اول

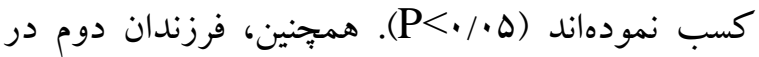
مقايسه با همتايان اول خود نمرات بالاترى را در شاخص نقص توجه بيش فعالى كانرز به دست آوردند

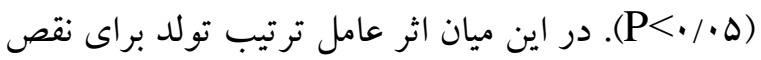

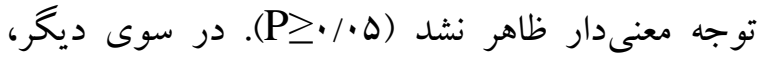
بيگيرى براى تعدد سابقه كيفرى نشان داد كه افراد با دو سابقه كيفرى و سه يا بيش از سه سابقه كيفرى از نمرات

جدول ه تحليل واريانس تك متغيره جهت مقايسه مجموع نقص توجه بيش فعالى تكانش كرى كانرز در افر اد مرتكب سرقت برحسب ترتيب تولد و تعدد سابقه كيفرى

منبع تغييرات




\begin{tabular}{|c|c|c|c|c|c|c|}
\hline معنىدارى & & مجذورات & آزادى & مجذورات & & \\
\hline.$/ \cdot 1 r$ & F/DrA & TYF/. Yr & r & $G 4 N / 4 Q$ & نقص توجه بيش فعالى تكانش گرى & ترتيب تولد \\
\hline.$/ .4 \Delta$ & $r / / 9 V$ & YYN/ATD & $r$ & $F \Delta V / 9 V I$ & نقص توجه بيش فعالى تكانش گرى & سابقه كيفرى \\
\hline
\end{tabular}

فرزندان اول اعمال نمايند با اين انگيزه كه به سابقهاى از تربيت سخت گيرانه دست يافته و همان شيوه را به منظور تحريكك تلاش در متولدين بعدى بكار برند و در نتيجه شاهد روش هاى مشابه تربيتى در كليه فرزندان باشيم (هاتز

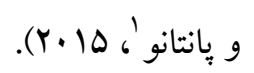
يافتهاى اين بُزوهش همجينين نشان دادند كه فرزندان

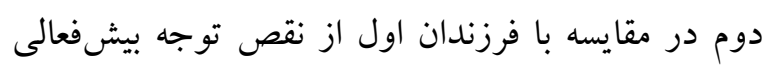
كودكى، بيش فعالى تكانش گرىى، شاخص نقص توجه بيش فعالى و نقص توجه بيش فعالى تكانش گرى بالاترى برخوردارند. فرزندان سوم نيز در قياس با فرزندان اول بيش فعالى تكانش گرى بيشترى را نشان دادند. در اين

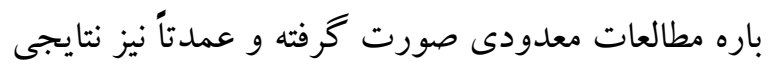

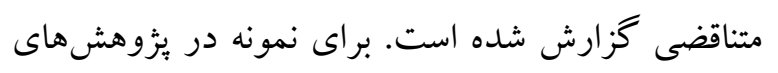

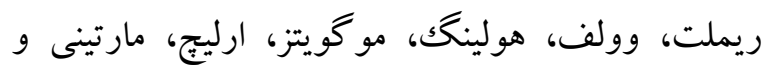
همكاران (YN) نى و همكاران (Y.|F) و كاربالو، كارسيا-نيتو، آلوارز كارسيا، كارو -كانيزارس، لويز -كاسترومن، مونوز-لورنزو

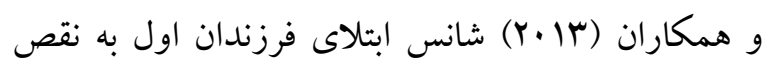
توجه-بيش فعالى بيش از متولدين بعدى كزارش شد. اما

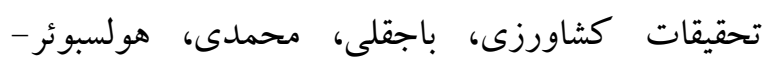

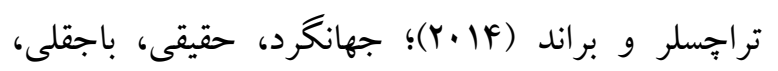

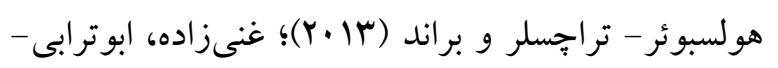
زرجى، محمدى و فيروزآبادى (Y (Y.Y) و بركر و فلسنتال

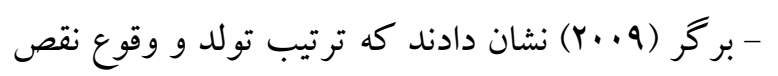
توجه - بيشفعالى ارتباط معنىدارى با يكديخر ندارند.

\footnotetext{
1. Hotz \& Pantano
}

همان طور كه جدول ه نشان مىدهد نسبتهاى محاسبه شده در مورد اثر عاملهاى ترتيب تولد و تعدد سابقه كيفرى براى متغير مجموع نقص توجه بيش فعالى تكانش گرى معنى كيفيت تفاوت بين ميانكينها مشخص شد كه در ميان فرزندان اول و دوم در مؤلفه نقص توجه بيش فعالى تكانش گرى كانرز تفاوت معنىدارى وجود دارد كه كوياى ميانخين بالاى نمرات اين مؤلفه در فرزندان دوم

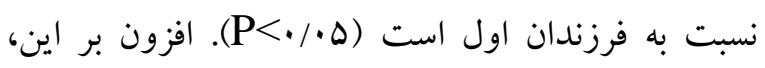
بيگيرى تفاوت بين ميانگينها براى عامل تعدد سابقه كيفرى نيز حكايت از آن داشت كه از نظر نقص توجه بيش فعالى تكانش گرى كانرز بين افراد با سابقه كيفرى يككبار و دو بار تفاوت معنىدارى وجود دارد كه اين تفاوت به ضرر افرادى بود كه از دو سابقه كيفرى

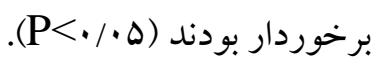

بر اساس يافتهاى به دست آمده، تفاوتى از نظر ميزان

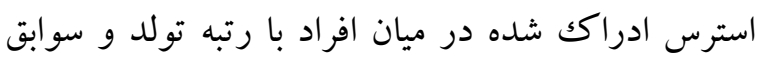
كيفرى مختلف كه مرتكب سرقت شدهاند، مشاهده نشد. اين موضوع مىتواند ناشى از سبكهاى مقابله يكسان، استفاده از روشهاى فرزنديرورى مشابه براى همه فرزندان يك خانواده و تعاملات ناجيز يا كيفيت بايين تعامل فرزندان با خانواده و در نتيجه كاستن از اثرات تربيتى خانواده باشد. براى مثال، برخى والدين ممكن

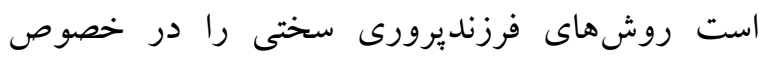


جايگًاه خود در خانواده مى جنگند (سولووى'، كونهاى كه ساز گارى هيجانى بيشتر براى فرزندان دوم امرى ناگزير بوده و رقابت براى توجه والدين را شامل مىشود. در سوى ديخر، افراد با دو سابقه كيفرى نسبت به افراد با يكك سابقه كيفرى از نقص توجه، شاخص نقص توجه بيشفعالى و نقص توجه بيش فعالى تكانش گرى بالاترى برخوردار بودند. همجنين سارقين با سه سابقه كيفرى و بيشتر نيز در مقايسه با تكك سابقهداران، نقص توجه بيش فعالى كودكى (وندر) و نقص توجه (كانرز) بيشترى را نشان دادند. در اين زمينه يثوهشهاى متعددى صورت كرفته و از ارتباط دوسويه ارتكاب به جرم و نقص توجهبيشفعالى حمايت نمودهاند. براى مثال، در مطالعات بيخيرانه (ساترفيلد، هوبِ و شل، 1919؛ ساترفيلد و شل، 199V

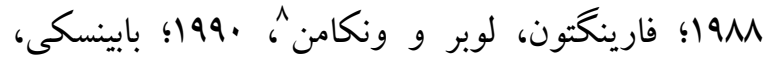

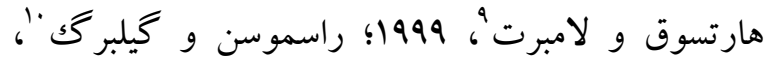

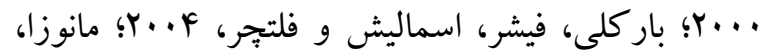
كلين و مولتون، ^^• (Y) مختلف همواره بر رابطه معنىدار بروز نقص توجه-بيشفعالى و گزارشهاى مربوط به سوء بيشينه قضايى اعم از حبس، دستگيرى و ارتكاب جرائم تاكيد شده است. در تبين اين يافتها مىتوان به نقش محيط زندان، تراكم اجتماعى و فضايى آن، كيفيت بايين خدمات قضايى دريافتى و احساس طردشدگى برآمده از خانو اده و اجتماع در ايجاد نايايدارى هيجانى، تظاهرات رفتارى برخاشگرانه و تنظيم هيجانى نامناسب در زندانيان اشاره كرد. به علاوه، بر اساس نظريه راسل

6- Sulloway

7. Moffitt \& Silva

${ }^{8}$ - Farrington, Loeber \& van Kammen

9 - Babinski, Hartsough \& Lambert

${ }^{10}$ - Rasmussen \& Gillberg
در تبيين تفاوتهاى حاصله از مطالعات مختلف نخست مى توان به كيفيت نمونهاى مورد بررسى اشاره كرد كه اكثر مطالعات بر روى دو گروه از كودكان و نوجوانان مبتلا به نقص توجه-بيش فعالى (ريملت، وولف،

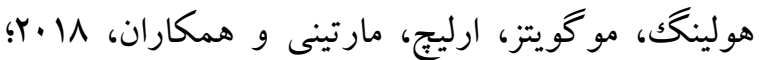

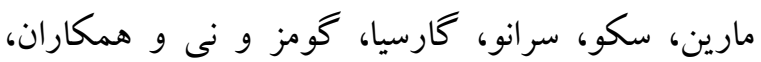

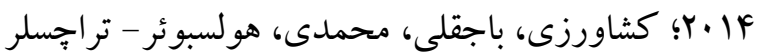

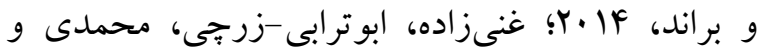

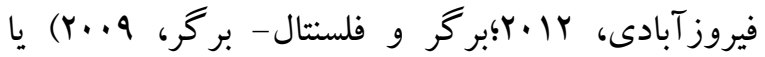
دانشجويان بزرگكسال جوان (جهانگرد، حقيقى، باجقلى، هولسبوئر - تراجسلر و براند، r|+r) تمركز يافتهاند؛ در حالى كه تا اين تاريخ مطالعه مشابهى بر روى افراد مرتكب سرقت در دسترس نيست و اين امر مىتواند در يافتهاى به دست آمده مؤثر بوده باشد. افزون بر اين،

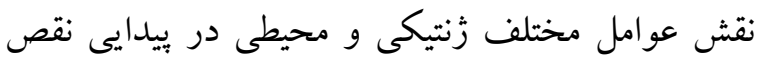
توجه - بيشفعالى نيز عمدتاً در مطالعات كنترل نشده يا غيرقابل كنترل بوده است. ئزوهشهاى مربوط به به

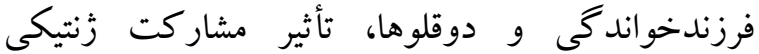
(فاراون، برليس، دويال، اسمولر، گورالنيك، هولمخرن'

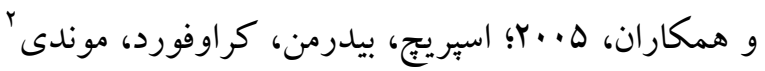
و فاراون، ....... و عوامل محيطى را برجسته ساختهاند

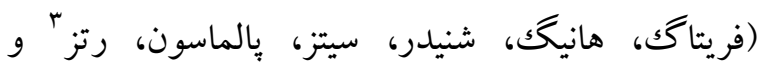

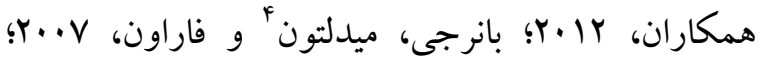

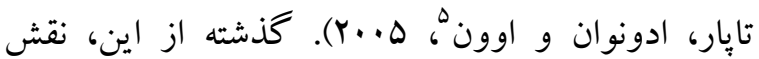
ترتيب تولد را مىتوان در قالب اثرات برآمده از رقابت

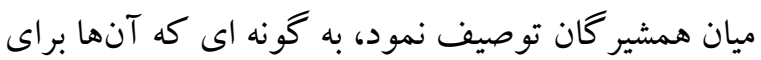

\footnotetext{
1- Faraone, Perlis, Doyle, Smoller, Goralnick \& Holmgren

2 - Sprich, Biederman, Crawford \& Mundy

3 - Freitag, Hänig, Schneider, Seitz, Palmason \& Retz

4- Banerjee \& Middleton

5. Thapar, O'donovan \& Owen
} 
كانرز، ساير مؤلفهاى نقص توجه بيش فعالى كودكى و

بزرگكالى در فرزندان دوم و سوم و افراد با دو و سه يا

بيش از سه سابقه كيفرى بيشتر از متولدين اول و افراد با

يكك سابقه كيفرى است. در حالى كه از نظر ميزان استرس

ادراكك شده بين اين گروهها تفاوت معنىدارى مشاهده

نشد. در اين راستا، اجراى مداخلات روانشناختى با هدف افز ايش ساز كارى زندانيان توصيه شد.

\section{سياسگز ارى}

بلدينوسيله از تمامى افرادى كه با حضور خود در اين يثزوهش ما را يارى كردند، سياسگزارى به عمل مى آيد. مطالعه حاضر بدون حمايت مالى خاصى انجام شده است

$$
\text { و با منافع نويسند گان ارتباطى ندارد. }
$$

\section{References}

Adler LA, Faraone SV, Spencer TJ, Michelson D, Reimherr FW, Glatt SJ, et al. (2008). The reliability and validity of self-and investigator ratings of $\mathrm{ADHD}$ in adults. Joumal of Attention Disorders, 11(6), 711-719.

Amin Yazdi SA. (1998). Relationship between documentaries styles with perceived stress. The final report of the research project. Mashhad: Ferdosi University. (Persian)

Babinski LM, Hartsough CS, Lambert NM. (1999). Childhood conduct problems, hyperactivityimpulsivity, and inattention as predictors of adult criminal activity. The Joumal of Child Psychology and Psychiatry and Allied Disciplines, 40(3), 347-355.

Banerjee TD, Middleton F, Faraone SV. (2007). Environmental risk factors for attention-deficit hyperactivity disorder. Acta Paediatrica, 96(9), 1269-1274.

Barkley RA, Fischer M, Smallish L, Fletcher K. (2004). Young adult follow-up of hyperactive children: antisocial activities and drug use.
بار كلى' مىتوان اثرات اشكال در خودتنظيمى'و نقص در فرآيندهاى بازدارى را نيز برجسته ساخت. بر اين اساس، تدوين برنامههاى درمانى و فراهمسازى تسهيلاتى به منظور افزايش سلامت روانى زندانيان در جهت ارزيابى، تشخيص و درمان آنها توصيه مىشود. از عمده محدوديتهاى اين مطالعه، مىتوان به عدم انجام مصاحبه بالينى با افراد مرتكب سرقت و در نتيجه عدم كزينش و جداسازى اختلالهاى همايند (رياحى، ايزدى

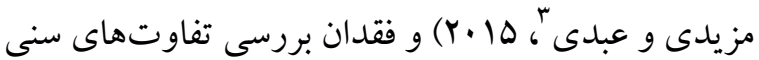
سنى بين همشير گان و سن تقويمى والدين در زمان تولد فرزندشان اشاره كرد. يارهاى از مطالعات نشان دادند كه

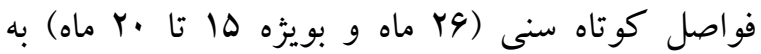

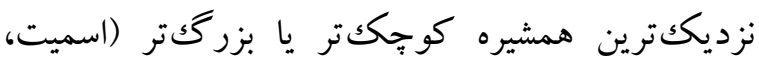

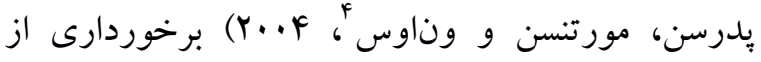

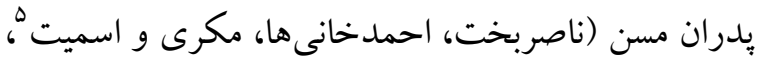

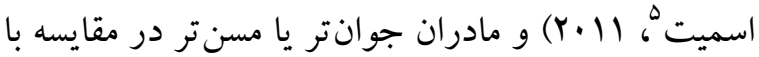

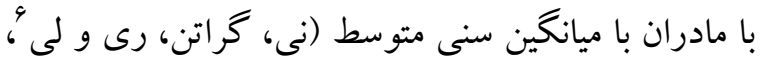

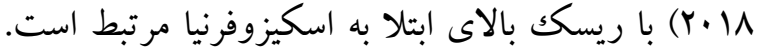
تحقيقات آتى مىبايست اين سؤال را به بوته آزمون نهند كه آيا سو گيرى تشخيصى در فرزندان اول، ميانى و آخر ناشى از افزايش توجه والدين، نامنى و اضطراب است يا خير.

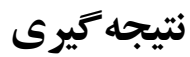

در مجموع، به استثناى رابطه ترتيب تولد با نقص توجه كانرز و تعدد سابقه كيفرى با بيش فعالى تكانش گرى برى

\footnotetext{
1- Russell Barkley's theory

${ }^{2}$ - Self-regulation

3. Riahi, Izadi-Mazidi \& Abdi

${ }^{4}$ - Smits, Pedersen, Mortensen \& van Os

5 - Naserbakht, Ahmadkhaniha, Mokri \& Smith

${ }^{6}$ - Ni, Gratten, Wray \& Lee
} 
45(2), 195-211.

Barkley RA. (2006). A theory of ADHD. IN: Barkley RA, Editor. Attention-Deficit Hyperactivity Disorder: A handbook for diagnosis and treatment. New York: The Guilford press, 297-334.

Bastani F, Gilani TH, Ghane-Fard S, Ghane-fard S. (2009). Perceived stress and demographic characteristics of women with multiple sclerosis. Advances in Nursing \& Midwifery, 19(66), 14-22.

Bayrami M, Goradel JA, Hashemi T, Alilu M. (2012). Predicting a tendency to use drugs from child and adult attention deficit hyperactivity disorder symptoms in adults. Intemational joumal of High Risk Behaviors \& Addiction, 1(3), 104-108.

Berger I, Felsenthal-Berger N. (2009). Attention-deficit hyperactivity disorder (ADHD) and birth order. Journal of Child Neurology, 24(6), 692696.

Carballo JJ, García-Nieto R, Álvarez-García R, CaroCañizares I, López-Castromán J, MuñozLorenzo L, et al. (2013). Sibship size, birth order, family structure and childhood mental disorders. Social Psychiatry and Psychiatric Epidemiology, 48(8), 1327-1333.

Cohen S, Kamarck T, Mermelstein R. (1983). A global measure of perceived stress. Journal of Health and Social Behavior, 24(4), 385-396.

Conners CK, Erhardt D, Sparrow EP. (1999). Conners' adult ADHD rating scales (CAARS): technical manual. New York: Multi-Health System Inc.

Cundiff PR. (2013). Ordered delinquency: The "effects" of birth order on delinquency. Personality and Social Psychology Bulletin, 39(8), 1017-1029.

Damian RI, Roberts BW. (2015). The associations of birth order with personality and intelligence in a representative sample of US high school students. Joumal of Research in Personality, 58,96-105.

Davari-Ashtiani R, Arabgol F, Razjouyan K, Khademi M, Jazayeri F. (2012). Evaluation of the Validity and Reliability of Adult ADHD
Journal of Child Psychology and Psychiatry, Rating Scales (Conners')-Persian version. Iranian Joumal of Psychiatry, 4(4), 38.

Farajiha M, Abedinezhad Mehrabadi Z. (2008). Managing the risk of criminals; Case study of the draft general section of the Islamic Penal Code Bill. Karagah, 2(5), 52-67. (Persian)

Faraone SV, Perlis RH, Doyle AE, Smoller JW, Goralnick JJ, Holmgren MA, et al. (2005). Molecular genetics of attentiondeficithyperactivity disorder. Biological psychiatry, 57(11), 1313-1323.

Farrington D, Loeber R, van Kammen WB. (1990). Long-term criminal outcomes of hyperactivity impulsivity- attention deficit and conduct problems in childhood. IN: Robins LN, Rutter M, Editors. Straight and Devious Pathways from Childhood to Adulthood. New York: Cambridge University press, 62-81.

Freitag CM, Hänig S, Schneider A, Seitz C, Palmason H, Retz W, et al. (2012). Biological and psychosocial environmental risk factors influence symptom severity and psychiatric comorbidity in children with ADHD. Journal of Neural Transmission, 119(1), 81-94.

Ghanizadeh A, Abotorabi-Zarchi M, Mohammadi MR, Firoozabadi A. (2012). Birth order and sibling gender ratio of a clinical sample of children and adolescents diagnosed with attention deficit hyperactivity disorder. Iranian Journal of Psychiatry, 7(3), 109.

Govek AC. (2012). Birth Order Impacts: Real or Imagined? A Review of Literature Past and Present. Graduate Joumal of Counseling Psychology, 3(1), 2.

Hechtman L, Weiss G, Perlman T. (1984). Hyperactives as young adults: Past and current substance abuse and antisocial behavior. American Journal of Orthopsychiatry, 54(3), 415.

Hotz VJ, Pantano J. (2015). Strategic parenting, birth order, and school performance. Joumal of Population Economics, 28(4), 911-936.

Jahangard L, Haghighi M, Bajoghli H, HolsboerTrachsler E, Brand S. (2013). Among a sample of Iranian students, adult attention 
deficit hyperactivity disorder is related to childhood ADHD, but not to age, gender, socioeconomic status, or birth order-An exploratory study. International Joumal of Psychiatry in Clinical Practice, 17(4), 273-278.

Keshavarzi Z, Bajoghli H, Mohamadi MR, HolsboerTrachsler, E, Brand S. (2014). Attention deficit hyperactivity disorder in children is found to be related to the occurrence of $\mathrm{ADHD}$ in siblings and the male gender, but not to birth order, when compared to healthy controls. International Journal of Psychiatry in Clinical Practice, 18(4), 272-279.

Mannuzza S, Klein RG, Moulton III JL. (2008). Lifetime criminality among boys with ADHD: a prospective follow-up study into adulthood using official arest records. Psychiatry Research, 160(3), 237.

Mansoor J. (2013). Islamic Penal Code (IPC). Tehran: Didar Publication. (Persian)

Marín AM, Seco FL, Serrano SM, García SA, Gómez AMG, Ney I. (2014). Do firstbom children have an increased risk of ADHD?. Joumal of Attention Disorders, 18(7), 594-597.

Marini VA, Kurtz JE. (2011). Birth order differences in normal personality traits: Perspectives from within and outside the family. Personality and Individual Differences, 51(8), 910-914.

Moffitt TE, Silva PA. (1988). Self-reported delinquency, neuropsychological deficit, and history of attention deficit disorder. Joumal of Abnormal Child Psychology, 16(5), 553-569.

Mozhdehi Fard M, Shooshtari MH, Najarzadegan MR, Khosravi T, Bidaki R, Moradi M, et al. (2017). Adult attention deficit hyperactivity disorder and suicide attempters: a case control study from Iran, West Asia. International Journal of High Risk Behaviors and Addiction, 6(1).

Naserbakht M, Ahmadkhaniha HR, Mokri B, Smith CL. (2011). Advanced paternal age is a risk factor for schizophrenia in Iranians. Annals of General Psychiatry, 10(1), 15.

Nejabati M. (2012). Criminal history and its impact on the system of legal punishment determination in Iran [dissertation]. Tehran: Tarbiat Modares University. (Persian)
Ni G, Gratten J, Wray NR, Lee SH. (2018). Age at first birth in women is genetically associated with increased risk of schizophrenia. Scientific Reports, 8(1), 10168.

Rasmussen P, Gillberg C. (2000). Natural outcome of ADHD with developmental coordination disorder at age 22 years: a controlled, longitudinal, community-based study. Joumal of the American Academy of Child \& Adolescent Psychiatry, 39(11), 1424-1431.

Reimelt C, Wolff N, Hölling H, Mogwitz S, Ehrlich S, Martini J, Roessner V. (2018). Siblings and Birth Order-Are They Important for the Occurrence of ADHD?. Joumal of Attention Disorders, 1087054718770020.

Riahi F, Izadi-Mazidi M, Abdi SM. (2015). Prevalence of comorbid psychiatric disorders in children and adolescents with attention deficit hyperactivity disorder. Jentashapir Journal of Health Research, 6(4), e25662.

Rossini ED, O'Connor MA. (1995). Retrospective selfreported symptoms of attention-deficit hyperactivity disorder. reliability of the Wender Utah Rating Scale. Psychological Reports, 77(3), 751-754.

Sarrami-Foroushani P. (2008). Normalizing and evaluating the validity and reliability of the Wender Utah Rating Scale to diagnose ADHD in adults in Isfahan.1999-2000 [Dissertation]. Isfahan, Iran: Isfahan University of Medical Sciences; 2008. (Persian)

Satterfield JH, Hoppe CM, Schell AM. (1982). A prospective study of delinquency in 110 adolescent boys with attention deficit disorder and 88 normal adolescent boys. The American Joumal of Psychiatry, 139, 795-798. Satterfield JH, Schell A. (1997). A prospective study of hyperactive boys with conduct problems and normal boys: adolescent and adult criminality. Journal of the American Academy of Child \& Adolescent Psychiatry, 36(12), 1726-1735.

Smits L, Pedersen C, Mortensen P, van Os J. (2004). Association between short birth intervals and schizophrenia in the offspring. Schizophrenia Research, 70(1),49-56. 
Sprich S, Biederman J, Crawford MH, Mundy E, Faraone SV. (2000). Adoptive and biological families of children and adolescents with ADHD. Joumal of the American Academy of Child \& Adolescent Psychiatry, 39(11), 14321437.

Sulloway FJ. (1996). Bom to rebel: Birth order, family dynamics, and creative lives. New York: Pantheon Books.

Thapar A, O'donovan M, Owen MJ. (2005). The genetics of attention deficit hyperactivity disorder. Human Molecular Genetics, 14(suppl_2), R275-R282. 